\title{
Synthesis, Characterization and AC conductivity of PVA based composite
}

\author{
S.Devikala ${ }^{1}$, P. Kamaraj ${ }^{2}$, M. Arthanareeswari ${ }^{3}$ \\ 1, 2,3 Department of chemistry, SRM University, Kattankulathur, 603 203, Tamil Nadu, India.
}

\begin{abstract}
Polyvinyl alcohol (PVA) / $\mathrm{ZrO}_{2}$ composites were prepared by sol gel method. The structural, micro structural and the dielectric properties of the composites were studied using $X$-ray diffraction(XRD), Scanning Electron Microscopy (SEM) and Hioki 3522-50 LCR Meter respectively. The electrical conductivity of composites has been investigated at different temperatures at frequency ranging from $50 \mathrm{~Hz}$ to $1 \mathrm{MHZ}$. The dielectric loss, dielectric constant and conductivity were changed with change in the concentration of $\mathrm{ZrO}_{2}$ and frequency of applied field. The electrical conductivities of the composites were found to increase with increasing temperature.
\end{abstract}

Keywords: $\mathrm{PVA}, \mathrm{ZrO}_{2}$, electrical conductivity, polymer composite

\section{Introduction}

Composites can be defined as materials that consist of two or more chemically and physically different phases separated by a distinct interface. Composites, the wonder materials are becoming an essential part of todays materials due to the advantages such as low weight, corrosion resistance, high fatigue strength, and faster assembly. They are extensively used as materials in making aircraft structures, electronic packaging to medical equipment, and space vehicle to home building. Composite materials having long-term durability for continuous purposes are desirable and cost-effective. There is much interest in the development of inexpensive composite polymers with an appropriate weight, appropriate electric conductivity and/or appropriate impact value for use with practical articles Itoh et al (2006a), Itoh et al (2006b), Kanda et al (2009). Polymer composites have steadily gained growing importance during the past decade. Vigorous developments of polymer composite and extensive utilization of polymer materials in technology have led to the polymer composites Wenderlinch (1973). The importance of polymers is mainly because polymers are still regarded as a cheap alternative material that is manufactured easily. The intensive use of polymer in broad use has led to the development of materials for specific applications namely composites Kryezewski (1975). Ceramic materials are typically brittle, possess low dielectric strength and in many cases are difficult to be processed requiring high temperature. On the other hand, polymers are flexible, can be easily processed at low temperatures and exhibit high dielectric break down field Mead (1961). A good amount of work has been reported on the conduction mechanism in polymeric materials. The electrical conduction in polymer film has much importance due to the discovery of the memory phenomenon and has wide applications now-a-days in thin film devices Chakraborty et al (1991). The electrical property of PVA composite has been reported (Navin etal 2011). The electrical conductivity of PVA-MWCNT with $\mathrm{MnO}_{2}$ as filler has been investigated (Mohd Faz etal). An electrical property of PVA based on LiFePO4 complex polymer electrolyte films has been reported (Mohan etal).

Chemicals and reagents

\section{Experimental}

PVA and $\mathrm{ZrO}_{2}$ were obtained from Alfa Aesar, India and used as such

\section{Preparation of PVAZ composites}

A definite quantity of PVA was dissolved in water at $60^{\circ} \mathrm{C}$ followed by the addition of a known quantity of $\mathrm{ZrO}_{2}$ and then it was made into a paste in an agate mortar then it was subjected to heat at $80^{\circ} \mathrm{C}$ for 30 minutes in a hot air oven and made into a powder. PVAT composites were prepared in the following proportions of PVA and $\mathrm{ZrO}_{2}$ : PVAZ 1 - 9:1, PVAZ 2 - 8:2, PVAZ 3 - 7:3, PVAZ 4 -6:4, , PVAZ 5 - 5:5 and PVAZ 6 4:6.

\section{PXRD}

In order to understand the properties of composite material, it is essential to know about the details of its structure. The X-ray diffraction pattern (XRD) technique was used for characterization. The PXRD of PVA, $\mathrm{ZrO}_{2}$ and PVAZ composites were recorded using Philips X'PERT PRO diffractometer with $\mathrm{Cu} \mathrm{K \alpha}(\lambda=1.54060$ $\AA)$ incident radiation. The XRD peaks were recorded in the $2 \theta$ range of $20^{\circ}-80^{\circ}$. 
SEM

The Scanning electron microscopy produces detailed photographs that provide important information about the surface structure. The morphology of PVA, $\mathrm{ZrO}_{2}$ and PVAZ composites are recorded using Philips XL30. The samples were gold plated before SEM observation.

Dielectric properties and conductivity measurements

The electrical conductivity of composites were measured using Hioki 3522-50 LCR Meter. Testing temperature ranged from 40 to $60{ }^{\circ} \mathrm{C}$ at frequency ranging from $50 \mathrm{~Hz}$ to $1 \mathrm{MHZ}$.

\section{Results And Discussion}

PXRD

The pure PVA showed a characteristic peak for an orthorhombic lattice centered at $2 \theta, 20^{\circ} \mathrm{C}$ indicating a semi crystalline nature (Fig.1). XRD of pure $\mathrm{ZrO}_{2}$ was shown in the figure 2. Peaks appear at 20:30, 35, 50

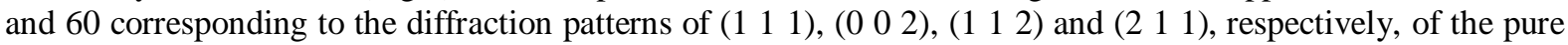

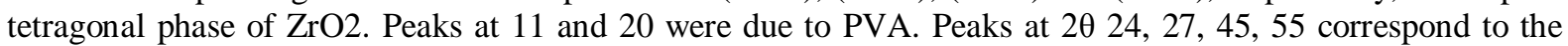
monoclinic phases of $\mathrm{ZrO}_{2}$. The peaks at 25, 38, 53 and 63 correspond to the anatase phase of $\mathrm{ZrO}_{2}$ and the peaks at 30, 35, 50, 59 correspond to the tetragonal phase of $\mathrm{ZrO}_{2}$ (Fig.3).

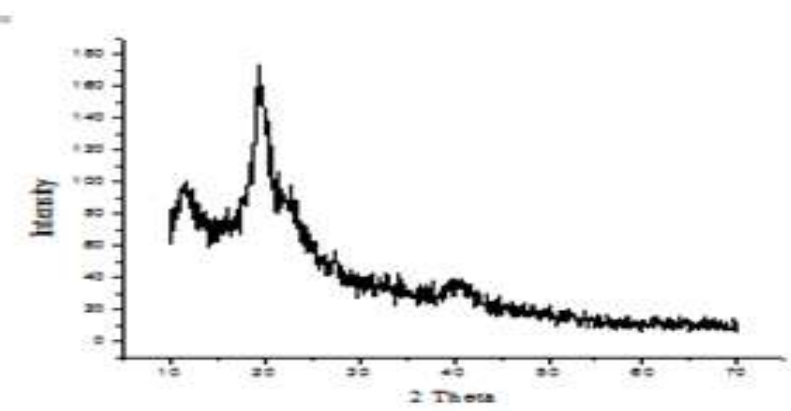

Fig. 1. XRD of PVA

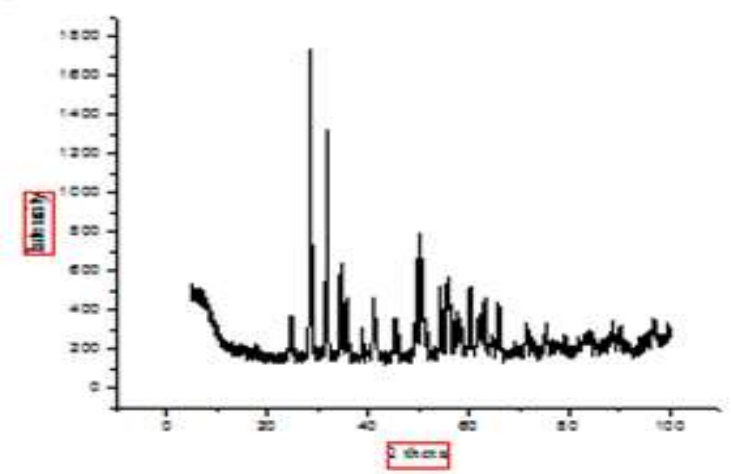

Fig. 2. XRD of $\mathrm{ZrO}_{2}$

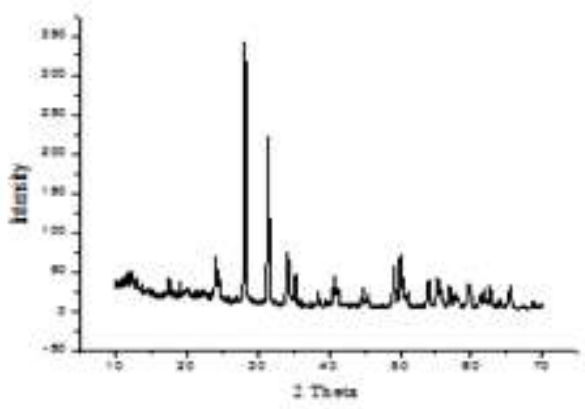

Fig. 3. XRD of PVAZ 6 


\section{SEM}

The SEM images of PVA, $\mathrm{ZrO}_{2}$ and the composite PVAZ 6 were shown in the figures 4,5 and 6 respectively. The SEM visualizes the presence of small ratio of secondary phase $\left(\mathrm{ZrO}_{2}\right)$ which was randomly distributed and get adhered on PVA matrix.

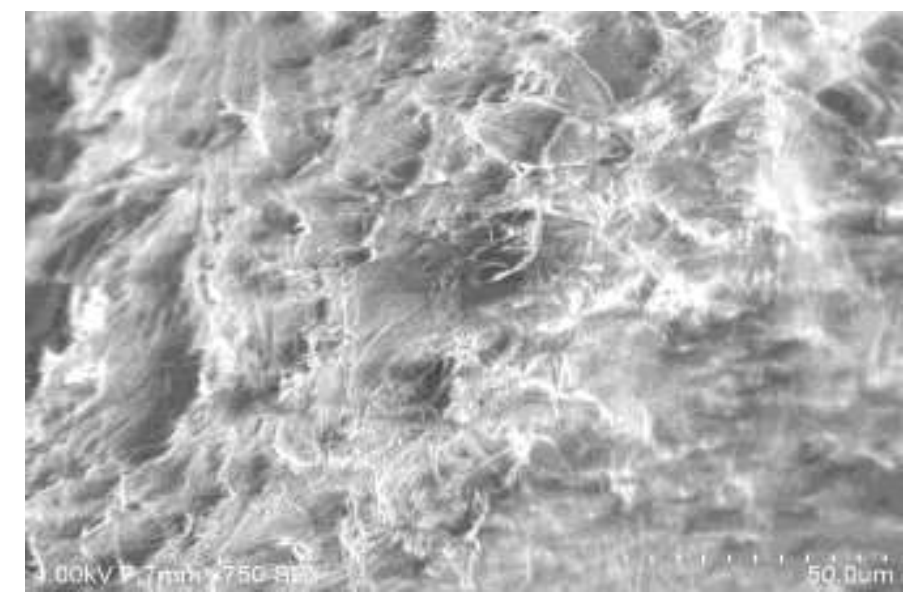

Fig. 4. SEM image of PVA

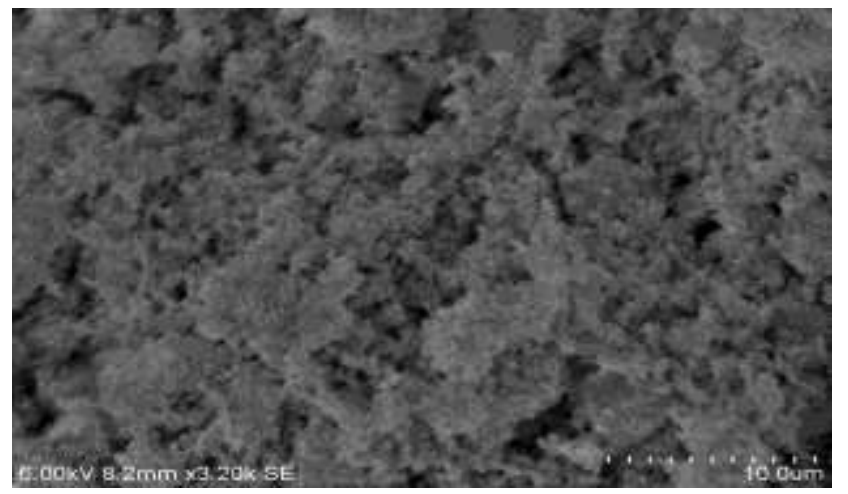

Fig. 5. SEM image of $\mathrm{ZrO}_{2}$

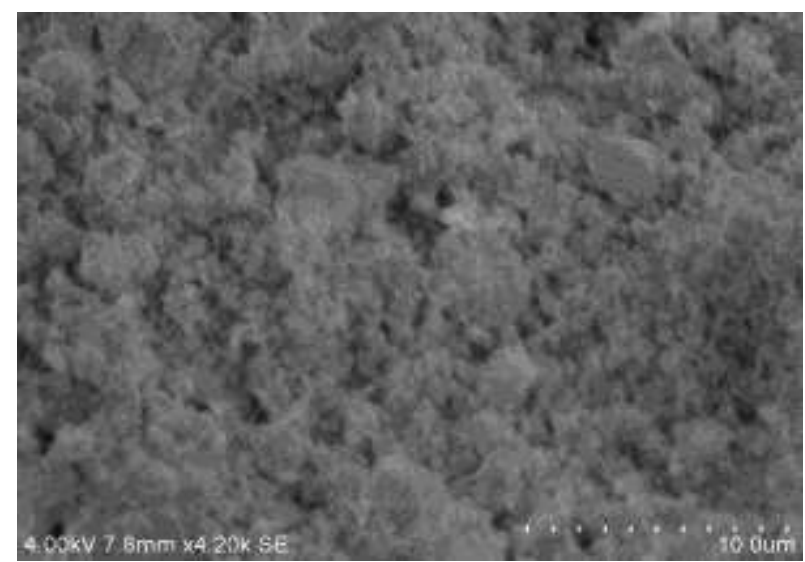

Fig. 6. SEM image of PVAZ 6

\section{AC conductivity of $\mathrm{PVA} / \mathrm{ZrO}_{2}$ composites}

The measured conductance $\mathrm{G}$, from $50 \mathrm{~Hz}$ to $5000000 \mathrm{~Hz}$ used to calculate ac conductivity, $\sigma(\mathrm{ac})$ using the following expression:

$\sigma(\mathrm{ac})=\mathrm{Gd} / \mathrm{A}$

Where $\mathrm{d}$ is the thickness of the sample and $\mathrm{A}$ is the cross sectional area of the electrode.

The AC conductivity of PVAZ composites at different temperatures were shown in Table 1. Polymer Materials in pure state are electrical insulators. However they are filled with specific additives, as Metallic powders metallic fibers, ionic conductive polymers, etc. The conductivity of pure PVA was found to be $9.73 \times 10^{-9} \mathrm{~S} / \mathrm{cm}$ 
the conductivity is found to increase with the temperature as well as filler concentration. The increase in conductivity with temperature is interpreted as a hopping mechanism between coordinate site, local structural relaxations, and segmental motion of the polymer. The observed continuous increase in conductivity of composites system with increasing $\mathrm{ZrO}_{2}$ concentration is attributed to a decrease in degree of crystallinity and increase in amorphisity and was confirmed by XRD studies. As amorphous region progressively increases, however the polymer chain acquires faster internal modes in which bond rotations produce segmental motion. This is turn favours hopping interchain and intrachain ion movements, and conductivity of polymer composites thus becomes high. The increase in conductivity with temperature may be explained based on the assumption that within the bulk, the oxygen vacancies due to the loss of oxygen, are usually created during increase in temperature and the charge compensation, which would leave behind free electrons. In metal oxides, electrical conduction occurs through strong coupling between phonons and electrons with the creation of polarons.

Table 1. shows the variation of conductivity with $\mathrm{ZrO}_{2}$ concentration for different temperatures.

\begin{tabular}{|l|l|l|l|}
\hline & \multicolumn{4}{l|}{ Conductivity (S/cm) } \\
\hline System studied & 313K & 323K & 333K \\
\hline PVAZ1 & $1.73 \times 10^{-9}$ & $1.351 \times 10^{-8}$ & $1.874 \times 10^{-7}$ \\
\hline PVAZ2 & $2.012 \times 10^{-9}$ & $2.218 \times 10^{-8}$ & $2.312 \times 10^{-7}$ \\
\hline PVAZ3 & $3.179 \times 10^{-9}$ & $3.447 \times 10^{-8}$ & $3.738 \times 10^{-7}$ \\
\hline PVAZ4 & $4.074 \times 10^{-9}$ & $4.426 \times 10^{-8}$ & $4.746 \times 10^{-7}$ \\
\hline PVAZ5 & $5.035 \times 10^{-9}$ & $5.330 \times 10^{-8}$ & $5.863 \times 10^{-7}$ \\
\hline PVAZ6 & $6.752 \times 10^{-9}$ & $6.922 \times 10^{-8}$ & $6.987 \times 10^{-7}$ \\
\hline
\end{tabular}

\section{Dielectric properties}

The higher value of dielectric constant was due to higher grain size. The dielectric constant strongly depends on the grain size. The dielectric constant of materials was due to the electronic, ionic, dipolar and surface charge polarizations which depend on the frequencies. The large value of dielectric constant at lower frequency may be due space charge polarization arising at the grain boundary interfaces. Figures 7 and 8 showed the variation of dielectric loss and dielectric constant as functions of frequency. In both the plots, the dielectric loss and dielectric constant decreases with the increase of frequency, which was in good agreement with the reported value Fang et al (2006).

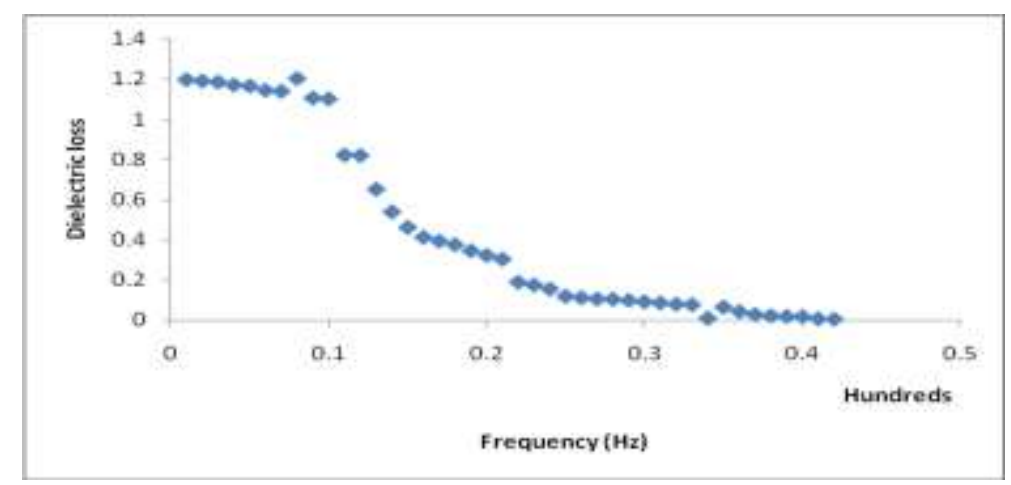

Fig. 7. Variation of dielectric loss with frequency at $333 \mathrm{~K}$ for PVAZ 6

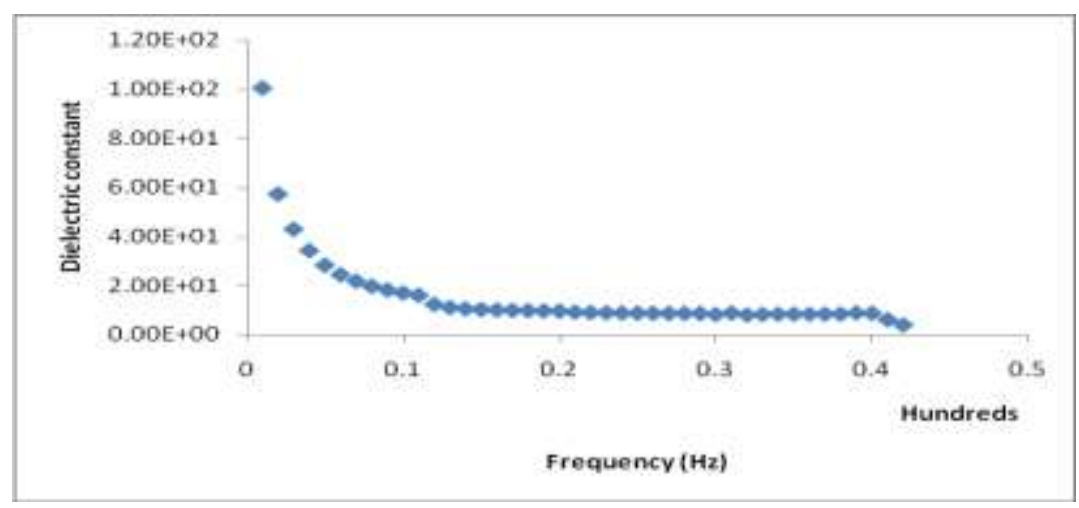

Fig. 8. Variation of dielectric constant with frequency at 333K for PVAZ 6 


\section{Conclusion}

Polyvinyl alcohol (PVA) / $\mathrm{ZrO}_{2}$ composites were prepared by sol gel method. The polymer composites were characterized using PXRD and SEM. The electrical conductivity and dielectric properties of the polymer composites were measured. The A.C electrical conductivity of the composites increased by increasing the $\mathrm{ZrO}_{2}$ concentrations and with increased temperature. As the temperature increased the charge carries were thermally activated and the free volume increases and more vacant sites are created for the motion of ions, which in turn enhanced the conductivity. The dielectric loss and dielectric constant decreased with the Increase of frequency. This was due to the electronic, ionic, dipolar and surface charge polarizations which depend on the frequencies. The larger value of dielectric constant at lower frequency may be due to space charge polarization arising at the grain boundary interfaces.

\section{References}

[1] K. Itoh, M. Kanda and Y. Nishi: (2006). J. Japan Inst. Metals. 70: 940-944.

[2] M. Kanda, K. Itoh and Y. Nishi: (2006).J. Japan Inst. Metals. 70: 945-949.

[3] M. Kanda and Y. Nishi: (2009). Mater. Trans. 50: 177-181.

[4] Wenderlinch B. (1973)."Macromolecular Physics", Academic press, New York.

[5] Kryezewski M. (1975) Polym. Sci. Polym. Symp. (USA) 50: 359

[6] Mead C A. (1961) J. Appl. Phys. USA 33: 646

[7] Chakraborty S C, Patil N B, Das S K and Basu S. (1991) Indian J.Pure \& Appl. Phys. 29: 478

[8] Navin Chand, Neelesh Rai, S L Agrawal and S K Patel, Bull. Mater. Sci., 34(7) 2011 1297-1304.

[9] Mohd Faiz Muaz Ahmad Zamri, Sharif Hussein Sharif Zein, Ahmad Zuhari Abdullah and Nor Irwin Basir, International journal of Engineering and Technology, IJET-IJENS 11(6) 20-26 2011

[10] Mohan V M, Weiliang Qiu, Jie Shen and Wen Chen, J Polym Res 2010, 17 143-150.

[11] S. M. El-Bashir and A. Hindi. (2010). Polymer-Plastics Technology and Engineering, 49:78-82.

[12] Pan YX, Yu ZZ, Ou YC, Hu GH. (2000). J. Polym Sci Part B: Polym Phys 38:1626-33.

[13] X S Fang, C H Ye, T Xie, ZY Wong, J W Zhao and L D Zhang. (2006).Appl. Phys. 188:013101-013103 